\title{
Exposure of spray operators to paraquat
}

\author{
A. A. B. SWAN \\ Imperial Chemical Industries Limited, Industrial Hygiene Research Laboratories, Alderley \\ Park, Macclesfield, Cheshire
}

\begin{abstract}
Swan, A. A. B. (1969). Brit. J. industr. Med., 26, 322-329. Exposure of spray operators to paraquat. Two field-trials in Malaysian rubber plantations are described in which operators applied paraquat for weed control with hand-operated knapsack sprayers. The extent of systemic absorption was assessed by weekly estimation of urinary paraquat concentrations during and after a 12-week period of continuous spraying. Periodic medical examinations, including chest radiographs, were made before and during the trials and for some weeks afterwards. The conditions of continuous operation with paraquat were probably close to the extremes of exposure likely to occur in any agricultural operation, but the investigations have shown that ordinary care in personal hygiene is sufficient to prevent any hazard from surface injury or from systemic absorption.
\end{abstract}

Since paraquat was first introduced into agricultural practice in 1961 few incidents of ill-effects in operators have been reported, and all have been due to the local irritant effects of the material.

Experimental investigation of skin penetration in rabbits has indicated that paraquat in dilute aqueous solution (approximately $0.3 \%$ ) does not penetrate intact skin (Clark, McElligott, and Hurst, 1966). Systemic effects can be produced by single applications of concentrated solution to the skin under occlusive dressings or by repeated application to the same area: in both cases some degree of local damage is probably produced by the application before penetration occurs (McElligott, 1967). It has also been shown that the addition of surface-active agents may enable some penetration of the intact skin to occur in animals (Conning, 1968). Since, in practice, paraquat is mostly used along with a surface-active 'wetting' agent and the likelihood of agricultural operators suffering from minor abrasions of the skin is high, it was thought necessary to investigate the extent to which paraquat might be absorbed systemically during spraying operations.

The use of paraquat in temperate agriculture is confined to relatively short periods of the year, and the method of application in the large-scale uses is such as to limit operator exposure to a minimum.
Malaysian rubber plantations were finally selected as being likely to represent much greater operator exposure, because weed control is required continuously for 10 months of the year and the herbicides are applied by gangs of men using 'knapsack' sprayers for the entire working day, usually six days a week. The light clothing, which must be worn because of the prevailing high temperature and humidity, increases the chances of skin contamination. Between the planning in 1964 of the first field investigation and the second in 1967, publication of several cases of fatal poisoning in man by accidental drinking of paraquat (Bullivant, 1966; Doyle and Lee, 1966) established the similarity of the lung injury produced in this way to the lesion evoked by parenteral administration in animals (Clark et al., 1966) and made it of still greater importance to attempt some measure of systemic absorption in agricultural operators.

\section{Site of investigations}

Dunlop Estates Berhad, Federation of Malaya, made available its Regent Estate for the investigations conducted in 1965, and its Regent and Bahau Estates, Negri Sembilan, for the further investigations in1967. Both estates cover an area of between 
5,000 and 6,000 acres of low hill country with the rubber trees laid out in uniform contour planting over much of the area. On Regent Estate, secondary vegetation was kept low, to an average height of less than one foot $(0.3 \mathrm{~m}$.); on Bahau the vegetation was denser and taller, and approached waist height in many places.

\section{Design of investigations}

The 1965 investigation was conducted as nearly as possible to average conditions of spraying. A team of six sprayers - two Chinese, two Indians, and two Malays was formed to include a range of skin pigmentation and of differing practice in personal hygiene. Clothing consisted of shirt, singlet, and long trousers tucked inside the socks; footwear varied from canvas or leather shoes to open sandals. This is the normal dress for such operations on Malaysian estates, which do not as a rule provide more elaborate protective clothing.

The men were expected to wash before and after spraying, but no other measures were advised, and handling and spraying practices were those of an average estate. Only the estate dresser in charge of the team handled the concentrated Gramoxone and made up a standard $1: 400$ dilution of paraquat. Saval knapsack sprayers with 'flood-jet' nozzles were used, the men walking forwards into the sprayed area all the time. The team worked six days a week for 12 weeks from June to September 1965.

The 1967 investigation was designed to show which route of exposure was the most important in determining absorption of the traces of paraquat found in the urine of some operators in the 1965 trials. Operations were carried out by four teams, one with normal clothing and the remaining three with the following combinations of protective equipment: knee-length gum boots and rubber gloves; face-mask ${ }^{1}$ and rubber gloves; face-mask and gum boots.

In addition, to investigate the influence on exposure of the type of vegetation being controlled by spraying, operations were conducted on two estates, one of which (Bahau) had taller and denser vegetation than the other (Regent Estate). As before, the teams were composed of two Chinese, two Indians, and two Malays, and half of each team worked on each estate. Equipment and procedures were otherwise the same as in the previous investigation, and the operations were continued for 12 to 13 weeks.

The usual height of weed growth controlled by spraying is shown in Fig. 1, which also illustrates the clothing normally worn by spray operators. Figure 2 shows the conditions of weed growth on the Bahau Estate during the trial. In both pictures it can be seen how the operator must walk continually into vegetation newly wetted with spray.

\footnotetext{
Medical examinations

In both investigations, each man was given a thorough physical examination before spraying began and at weekly intervals throughout. All operators had chest radiographs (antero-posterior and lateral) before starting work and at the end of the sixth and twelfth weeks.

${ }^{1}$ Siebe-Gorman Filtasafe dust respirator.
}

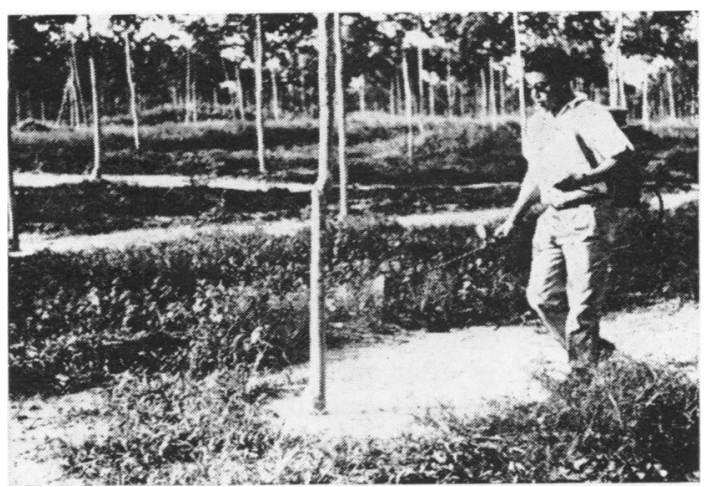

FIG. 1. 1967 trial. Spray operator on Regent Estate; normal clothing and normal height of weed growth.

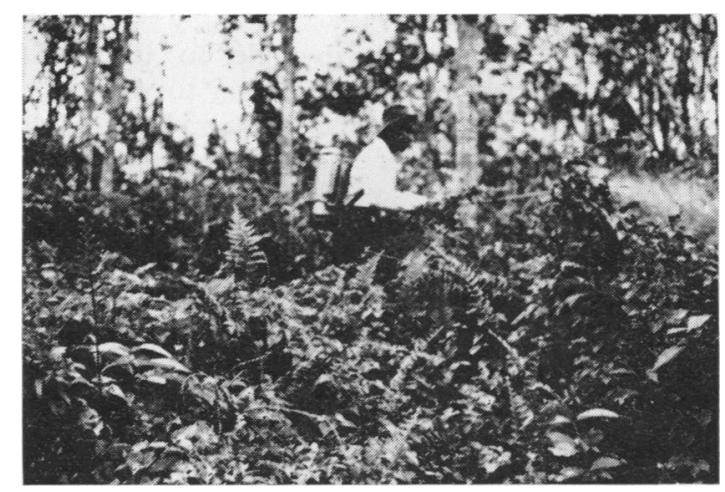

FIG. 2. 1967 trial. Operator on Bahau Estate showing the unusually tall weed growth.

Urine samples were collected under strict supervision for paraquat analysis, and stringent precautions were taken to avoid accidental contamination. Individual specimens were collected directly into polythene bottles containing a small amount of thymol to inhibit bacterial growth. Analysis of paraquat content was carried out, using the method of Calderbank and Yuen (1965). The method is capable of determining $2.5 \mu \mathrm{g}$. paraquat with certainty, so that, depending on the volume of urine sample, a concentration of 0.01 p.p.m. could be measured in most cases, and in a few cases 0.02 p.p.m. when a smaller volume was provided. The first samples were collected two days before spraying began and at weekly intervals until spraying ceased. After spraying ceased in 1965 , daily samples were taken during the first week and at weekly intervals during the following month; in 1967, samples were taken twice weekly for two weeks after the end of spraying.

\section{Results}

\section{5 trials}

The collected results of urine analysis and records of the amount of diluted Gramoxone solution sprayed by individual members of the six-man team are presented in Table 1. Small amounts of paraquat 
were found in the urine of all members of the team at some stage during the 12-week spraying period. The average amount of diluted Gramoxone solution sprayed by each man during the period was just under 2,600 gallons. The highest concentration of paraquat found was 0.32 p.p.m., and most were well below $0 \cdot 1$ p.p.m. Paraquat was not detected in some of the urine samples taken during spraying, and there was no rising trend in the amounts found as the operations continued. Residues were found in the first few days after spraying ceased in the five operators showing residues in the last week of spraying. With one exception, these declined steadily to undetectable levels within a week. In one man, no residues were found on days 4 to 7 after spraying, were detected again in weekly samples taken from the second to the fifth week, and thereafter could not be detected.

Only two episodes attributable to the local effects of paraquat occurred. Owing to a leaking joint at the connexion of tubing and spray tank, one operator in the first week of operations worked for the greater part of a day wearing trousers continually soaked in dilute spray solution. He developed dermatitis of the scrotum which required a period of 14 days' in-patient hospital treatment. When this man resumed work, further contact with the solution produced some itching of the skin of the hands and some desquamation of the skin of one ear through rubbing the ear with contaminated hands, but after the fifth week no further trouble was experienced for the rest of the operation. The estate dresser, who was responsible for preparing the spray solution, was involved in the other episode and required medical attention for a severe epistaxis which occurred after he had been making up the diluted spray in an enclosed space and had probably inhaled some droplets produced by splashing of the concentrate. In a sample of urine collected seven days later, 0.04 p.p.m. paraquat was found; he had, however, continued to handle Gramoxone in the interval. The making up of spray dilutions was subsequently carried out in the open and no further trouble was experienced. No abnormalities were seen in the chest radiographs throughout the operation.

\section{7 trials}

The collected observations and records of Gramoxone usage are presented in Tables 2 to 5 . The average amount of diluted Gramoxone sprayed by each operator during the 13 to 14 weeks of the operation was just under 1,800 gallons - considerably less than in the earlier investigation. The extent to which paraquat was found in urine samples was also considerably less; in a total of 394 samples, it was detected in only 53 and the highest concentration found was 0.15 p.p.m. This compares with a total of 134 samples in which it was found on

TABLE 1

Gramoxone Spraying Trial (Regent Estate) 1965

\begin{tabular}{|c|c|c|c|c|c|c|c|c|c|c|c|c|c|c|c|c|c|c|c|c|c|}
\hline \multirow{3}{*}{ Subject } & \multicolumn{12}{|c|}{$\begin{array}{l}\text { Paraquat residues in urine in p.p.m. } \\
\text { Gallons of Gramoxone sprayed per week }\end{array}$} & \multicolumn{8}{|c|}{ Paraquat in urine post-spraying } & \multirow{3}{*}{$\begin{array}{c}\text { Total } \\
\text { sprayed } \\
\text { (gallons) }\end{array}$} \\
\hline & \multicolumn{12}{|c|}{ Week } & \multicolumn{8}{|c|}{ Day } & \\
\hline & 1 & 2 & 3 & 4 & 5 & 6 & 7 & 8 & 9 & 10 & 11 & 12 & $I$ & 2 & 3 & 4 & 5 & 6 & 7 & 14 & \\
\hline I.b.L. & $\begin{array}{l}0 \cdot 19 \\
147\end{array}$ & $\begin{array}{c}0.2 \\
\dagger \\
235\end{array}$ & $\begin{array}{l}0 \cdot 11 \\
217\end{array}$ & $\begin{array}{r}<0.02 \\
248\end{array}$ & $\begin{array}{l}0 \cdot 14 \\
203\end{array}$ & $\begin{array}{c}0.18 \\
\dagger \\
252\end{array}$ & $\begin{array}{l}0.32 \\
263\end{array}$ & $\begin{array}{c}0.15 \\
t \\
238\end{array}$ & $\begin{array}{l}0.02 \\
220\end{array}$ & $\begin{array}{l}0.06 \\
210\end{array}$ & $\begin{array}{r}<0.01 \\
42\end{array}$ & $\begin{array}{l}0 \cdot 19 \\
259\end{array}$ & 0.3 & $0 \cdot 12$ & 0.11 & 0.07 & 0.05 & $<0.01$ & 0.02 & $<0.01$ & 2,534 \\
\hline C. & $\begin{array}{c}<0.01 \\
\ddagger \\
151\end{array}$ & $\begin{array}{c}<0.01 \\
\text { nil }\end{array}$ & $\begin{array}{r}0.01 \\
42\end{array}$ & $\begin{array}{l}0.03 \\
\ddagger \\
249\end{array}$ & $\begin{array}{c}0.03 \\
199\end{array}$ & $\begin{array}{l}0.04 \\
252\end{array}$ & $\begin{array}{l}0.07 \\
259\end{array}$ & $\begin{array}{l}0.04 \\
242\end{array}$ & $\begin{array}{l}0.01 \\
217\end{array}$ & $\begin{array}{l}0.03 \\
210\end{array}$ & $\begin{array}{c}0.03 \\
255\end{array}$ & $\begin{array}{l}0.08 \\
259\end{array}$ & 0.11 & 0.03 & 0.04 & 0.03 & 0.03 & $\longrightarrow$ & $<0.01$ & & 2,335 \\
\hline K. & $\begin{array}{l}0 \cdot 01 \\
182\end{array}$ & $\begin{array}{l}0 \cdot 02 \\
235\end{array}$ & $\begin{array}{l}0 \cdot 03 \\
213\end{array}$ & $\begin{array}{c}<0.02 \\
252\end{array}$ & $\begin{array}{l}0.02 \\
200\end{array}$ & $\begin{array}{l}0.04 \\
252\end{array}$ & $\begin{array}{l}0.06 \\
259\end{array}$ & $\begin{array}{l}0.03 \\
238\end{array}$ & $\begin{array}{l}0.02 \\
126\end{array}$ & $\begin{array}{l}0 \cdot 03 \\
210\end{array}$ & $\begin{array}{c}<0.01 \\
192\end{array}$ & $\begin{array}{l}0 \cdot 07 \\
252\end{array}$ & 0.04 & 0.03 & 0.02 & 0.03 & 0.02 & $\longrightarrow$ & $<0.01$ & & 2,611 \\
\hline C.L. & $\begin{array}{l}0.03 \\
168\end{array}$ & $\begin{array}{c}<0.01 \\
231\end{array}$ & $\begin{array}{l}0.02 \\
214\end{array}$ & $\begin{array}{l}0.04 \\
252\end{array}$ & $\begin{array}{c}<0.01 \\
203\end{array}$ & $\begin{array}{l}0 \cdot 05 \\
248\end{array}$ & $\begin{array}{l}0.03 \\
259\end{array}$ & $\begin{array}{l}0.02 \\
238\end{array}$ & $\begin{array}{c}<0.02 \\
214\end{array}$ & $\begin{array}{l}0.01 \\
210\end{array}$ & \multicolumn{2}{|c|}{$-\underset{259}{<0 \cdot 01-} \mid 252$} & \multicolumn{8}{|c|}{$<<0.01$} & 2,748 \\
\hline Y.K.K. & $\begin{array}{l}0.04 \\
161\end{array}$ & $\begin{array}{l}0.01 \\
238\end{array}$ & $\begin{array}{l}0.01 \\
217\end{array}$ & $\begin{array}{c}<0.01 \\
\S \\
210\end{array}$ & $\begin{array}{c}0.03 \\
\S \\
207\end{array}$ & $\begin{array}{l}0.01 \\
255 \\
\end{array}$ & $\begin{array}{r}<0.01 \\
168 \\
\end{array}$ & $\begin{array}{l}0.02 \\
193 \\
\end{array}$ & \multicolumn{2}{|c|}{\begin{tabular}{r|r}
$-<0.02-$ \\
213 & 210
\end{tabular}} & $\begin{array}{r}<0.01 \\
259 \\
\end{array}$ & $\begin{array}{l}0.05 \\
252 \\
\end{array}$ & 0.01 & \multicolumn{7}{|c|}{$-<0.01-$} & 2,583 \\
\hline S.b.D. & $\begin{array}{l}0.04 \\
172\end{array}$ & $\begin{array}{l}0.02 \\
238\end{array}$ & $\begin{array}{l}0.03 \\
217\end{array}$ & $\begin{array}{l}0 \cdot 15 \\
252\end{array}$ & $\begin{array}{l}0.08 \\
203\end{array}$ & $\begin{array}{l}0 \cdot 1 \\
252\end{array}$ & $\begin{array}{l}0 \cdot 06 \\
263\end{array}$ & $\begin{array}{l}0.05 \\
238\end{array}$ & \multicolumn{2}{|c|}{$\begin{array}{r}-<0 \cdot 02- \\
220 \mid 210\end{array}$} & $\begin{array}{l}0.03 \\
259\end{array}$ & $\begin{array}{l}0.07 \\
238\end{array}$ & 0.06 & 0.04 & 0.02 & \multicolumn{4}{|c|}{$-<0.01$} & $0.04^{*}$ & 2,762 \\
\hline
\end{tabular}

-Residues of $0.05,0.11$ and 0.23 found on $3 \mathrm{rd}, 4$ th and 5 th weeks.

tFrictional lacerations of hands and back, and scratches by grass (2nd week); lacerations of feet (6th week); septic sores and dermatitis (8th week). fIn-patient in hospital during 2nd week-chemical dermatitis of scrotal skin; pruritus of skin of hands and desquamation of skin of ear (4th week). \$Small abrasion of shoulder (4th week); laceration of feet (5th week). 
78 occasions with a maximum concentration of 0.32 p.p.m. in the earlier trial. The highest percentage of 'positive' urine samples was found in the group wearing normal clothing and working on the estate with the denser weed growth $(50 \%$ : Bahau); this compares with $18 \%$ of 'positive' samples in the corresponding group on Regent Estate. The groups on Bahau wearing masks and gloves, and boots and gloves, had $14 \%$ and $10 \%$ of positive urines; in all other groups paraquat was detected in just over $7 \%$ of samples. After spraying ceased, a residue was found in only one specimen, collected on the second day in a member of the group wearing boots and gloves and working on the estate with the lower weed growth (Regent).

In the group wearing normal clothing, which included canvas shoes, there were three complaints of skin irritation (in one case from contaminated shoes) which resulted in an urticarial reaction followed by itching for a few days; in another, contamination of the hand by solution from a leaking valve gave rise to a burning sensation of the skin without visible injury. The third episode, a mild dermatitis of the genitalia, resulted from the continued wearing of contaminated trousers. In the remaining groups there were four more cases of mild skin irritation attributable to contact with the spray solution during work, in no case lasting more than a week.

One case of epistaxis occurred in the group wearing boots and gloves. He was the lowest in a line of 12 men when spraying was being carried out

TABLE 2

Gramoxone Spraying Trial 1967

(NoRMal Clothing)

\begin{tabular}{|c|c|c|c|c|c|c|c|c|c|c|c|c|c|c|c|c|}
\hline \multirow{3}{*}{ Subject } & \multicolumn{14}{|c|}{$\begin{array}{l}\text { Paraquat residues in urine in p.p.m. } \\
\text { Gallons of Gramoxone sprayed per week }\end{array}$} & $\begin{array}{c}\text { Paraquat in } \\
\text { urine } \\
\text { post-spraying }\end{array}$ & \multirow{3}{*}{$\begin{array}{c}\text { Total } \\
\text { sprayed } \\
\text { (gallons) }\end{array}$} \\
\hline & \multicolumn{14}{|c|}{ Week } & Day & \\
\hline & 1 & 2 & 3 & 4 & 5 & 6 & 7 & 8 & 9 & 10 & 11 & 12 & 13 & 14 & $\begin{array}{llll}2 & 5 & 9 & 12\end{array}$ & \\
\hline $\begin{array}{l}\text { Regent } \\
\text { Estate } \\
\text { M.b.A. }\end{array}$ & 201 & $\stackrel{\dagger}{186}$ & 117 & 168 & $\cdot 01$ & 192 & 75 & 105 & $\begin{array}{l}0.02 \\
273\end{array}$ & $\begin{array}{c}<0.01 \\
\dagger \\
174\end{array}$ & $\begin{array}{c}<0.01 \\
\dagger \\
249\end{array}$ & $\begin{array}{l}0.01 \\
150\end{array}$ & $\begin{array}{r}<0.01 \\
0\end{array}$ & - & $-<0.01-$ & 1,563 \\
\hline P. & $\begin{array}{c}<0.01 \\
\ddagger \\
202\end{array}$ & $\begin{array}{l}0 \cdot 01 \\
\ddagger \\
153\end{array}$ & $\begin{array}{r}<0.01 \\
111\end{array}$ & $\begin{array}{c}<0.01 \\
\ddagger \\
99\end{array}$ & $\begin{array}{l}0 \cdot 02 \\
102\end{array}$ & $\begin{array}{l}0.04 \\
\ddagger \\
213\end{array}$ & $\begin{array}{c}<0.01 \\
\ddagger \\
135\end{array}$ & $\begin{array}{l}0.01 \\
\ddagger \\
99\end{array}$ & $\begin{array}{c}0.02 \\
\ddagger \\
192\end{array}$ & 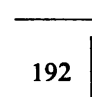 & $-<0$. & $01-$ & - & - & $-<0.01-$ & 1,546 \\
\hline A.C. & $\stackrel{\S}{188}$ & 172 & 105 & 54 & 33 & 192 & 153 & 171 & $\stackrel{\S}{243}$ & 327 & $\stackrel{\S}{\$} 252$ & 246 & 156 & 一 & $-<0.01-$ & 1,796 \\
\hline $\begin{array}{c}\text { Bahau } \\
\text { Estate } \\
\text { S.b.Y. }\end{array}$ & $\begin{array}{r}<0.01 \\
0\end{array}$ & $\begin{array}{r}<0.01 \\
195\end{array}$ & $\begin{array}{l}0.01 \\
\dagger \\
206\end{array}$ & $\begin{array}{l}0.01 \\
162\end{array}$ & $\begin{array}{l}0.03 \\
192\end{array}$ & $\begin{array}{r}0.02 \\
45\end{array}$ & 174 & $<0$ & $01-$ & - & $\begin{array}{l}0 \cdot 02 \\
219\end{array}$ & $\begin{array}{c}0 \cdot 07 \\
\dagger \\
207\end{array}$ & $\begin{array}{r}<0.01 \\
189\end{array}$ & $\begin{array}{l}0.04 \\
117\end{array}$ & $-<0.01-$ & 1,272 \\
\hline R. & \multicolumn{4}{|c|}{$-<0.01-1$} & $\begin{array}{l}0.01 \\
244\end{array}$ & $\begin{array}{r}0.02 \\
45\end{array}$ & $\begin{array}{l}0.02 \\
219\end{array}$ & $\begin{array}{r}<0.01 \\
195\end{array}$ & $\begin{array}{l}0.02 \\
132\end{array}$ & $\begin{array}{l}0.08 \\
276\end{array}$ & $\begin{array}{l}0.02 \\
216\end{array}$ & $\begin{array}{l}0.06 \\
207\end{array}$ & $\begin{array}{c}<0.01 \\
\ddagger \\
183\end{array}$ & $\begin{array}{l}0.01 \\
174\end{array}$ & $* \quad<0.01$ & 2,554 \\
\hline C.K.N. & $\begin{array}{r}<0.01 \\
66\end{array}$ & $\begin{array}{c}<0.01 \\
\S \\
186\end{array}$ & $\begin{array}{l}0 \cdot 04 \\
\S \\
219\end{array}$ & $\begin{array}{l}0.09 \\
171\end{array}$ & $\begin{array}{c}0 \cdot 13 \\
72\end{array}$ & $\begin{array}{r}<0.01 \\
0\end{array}$ & $\begin{array}{c}0.07 \\
\S \\
174\end{array}$ & $\begin{array}{r}<0.01 \\
141\end{array}$ & $\begin{array}{l}0.08 \\
174\end{array}$ & $\begin{array}{l}0 \cdot 15 \\
\S \\
210\end{array}$ & $\begin{array}{r}<0.01 \\
219\end{array}$ & $\begin{array}{c}0.08 \\
\S \\
213\end{array}$ & $\begin{array}{c}<0.01 \\
180\end{array}$ & $\begin{array}{r}<0.01 \\
135\end{array}$ & $-<0.01-$ & 2,160 \\
\hline
\end{tabular}

Regent

tCut on thumb (2nd week); abrasion on leg (10th week); abrasion on hand and solution in eye (11th week)

†Small scratch on leg (1st week); small injury to foot (2nd week); injury to leg (4th week); hand contaminated from faulty pump (6th week); toe abrasion (7th and 8th weeks); spray solution in eye (9th week); loss of pigment on finger (12th week).

§Desquamation of skin on hand (1st week); shoes contaminated, slight foot irritation (9th week); skin irritation on right leg and injury to both feet (11th week).

Bahau

*Insufficient sample.

†Friction wound on toe (3rd week); friction wound on shoulder (12th week).

†Skin irritation from spillage on thigh, laceration on foot (13th week).

$\S$ Small cut on thumb web of each hand ( 2 nd week); boot friction wound on shin (3rd week); small cut on foot (7th week); desquamation of skin of palm caused by gloves (10th week); minor abrasions on hands, cut on leg (12th week). 
on a steep hill-side with a breeze blowing down-hill. When first seen the nasal mucosa was intensely congested, an appearance similar to that found in the estate dresser in the earlier experiment, but it returned to normal after a few days. Further trouble of this sort was avoided by spraying steep places in échelon, down-hill man leading.

Over the whole period of operation there were seven instances of spray solution entering the eyes. These were treated by instillation of antibiotics (either oxytetracycline or hydrocortisone and neomycin drops) and in all cases recovery was complete in 24 to 48 hours. No cases involving the concentrate occurred since this was handled with appropriate precautions only by the estate dresser.

Chest radiographs taken before, during, and at the end of operations were in all cases normal, as was the chest radiograph of the operator who experienced nose-bleeding in the third week (L.b.L., Table 3) and who complained at the same time of chest pains. The four other complaints of chest pain recorded in this investigation were related to the presence of upper respiratory infections and coughing.

\section{Discussion}

Both trials have shown that it is through the local irritant properties of paraquat on the skin and eyes that effects are likely to arise in the field. Approximately half the men employed had some irritation of skin or eyes at some time during the trials. With the exception of the two cases of scrotal dermatitis, produced by exceptionally prolonged contact, all

TABLE 3

Gramoxone Spraying Trial 1967 (GuM BOOTS AND Gloves)

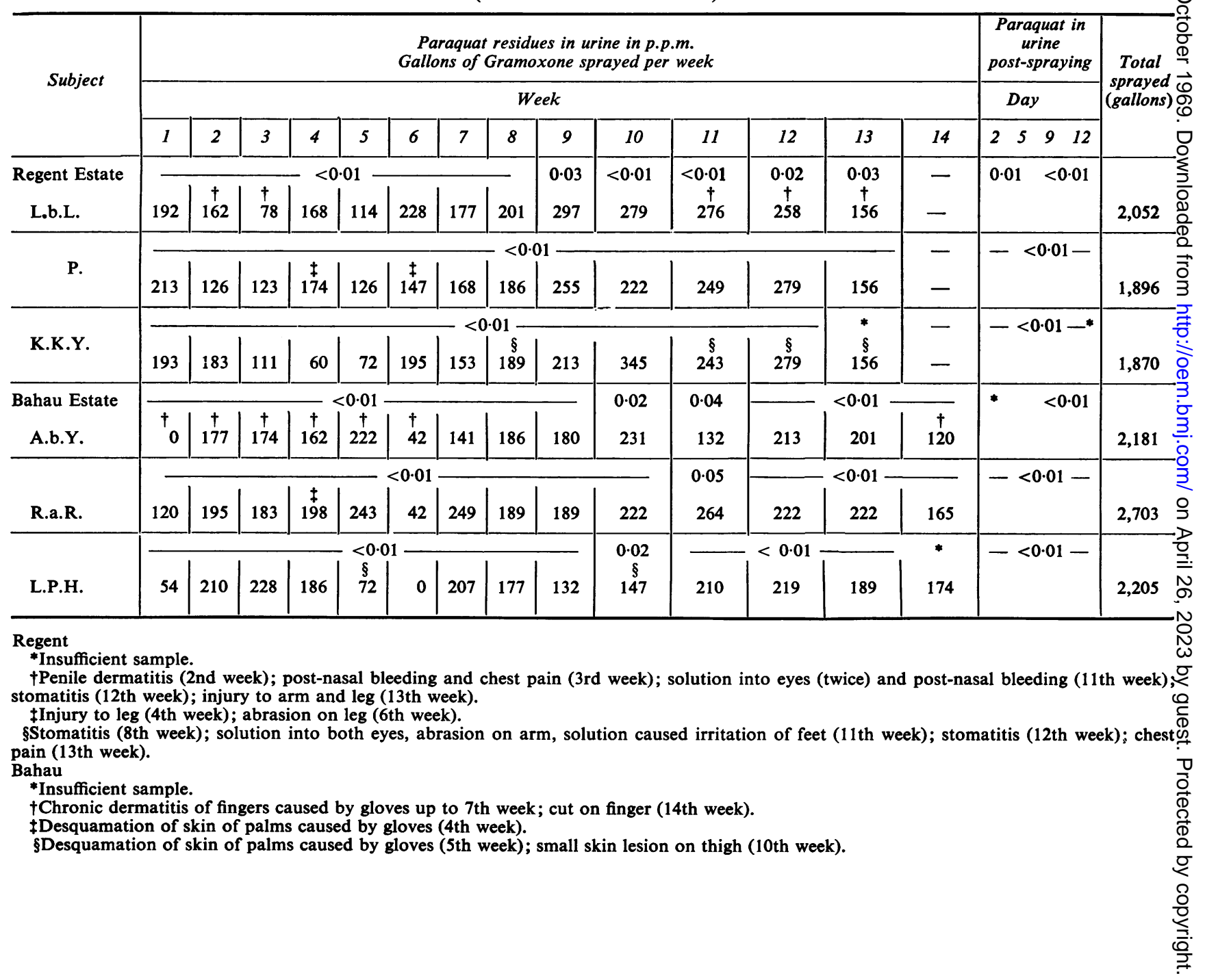


the skin irritations were mild and cleared rapidly with treatment. All cases of eye irritation were caused by the dilute spray and recovered within 24 to 48 hours, in contrast to the severe irritation and injury described by Sturman (1966) and Cant and Lewis (1968) following splashes of the concentrated formulation (Gramoxone) in the eye.

The extent of systemic absorption, indicated by the levels of paraquat found in the urine in both trials, was small. As the method of analysis is capable of detecting 0.01 p.p.m. paraquat, extreme care is required in field conditions to avoid accidental contamination of urine samples, and the occurrence of the two cases of penile dermatitis during the collection of urine recorded in the second trials, as a result of failure to observe the prescribed routine, suggests that even in supervised investigations the possibility that some of the paraquat-positive urines may have been due to chance contamination cannot be completely excluded. In the first trial, however, the continued presence of traces of paraquat in the urine in four of the six operators for several days after spraying ceased was evidence that systemic absorption had occurred. The reappearance of paraquat in the urine of one member of this team in the absence of further exposure was an unexplained finding.

The results of the 1967 investigation, particularly in the group wearing normal clothing, illustrate the reduction in exposure that can result from a relatively minor increase in care and discipline, especially as half of this group operated over the same ground as in the 1965 investigation. No conclusion on the most important site of absorption emerged from the 1967 investigation, partly because the extent of absorption was small in all groups. There was no evidence to suggest that any absorption occurs from the inhalation of spray droplets in this type of spraying, except in the single unusual circumstance described of operation on a steep hill-side. There is an indication in the incidence of positive urines that height of vegetation played a part in determining the

TABLE 4

Gramoxone SPRAying Trial 1967

(FACE MASKS AND Gloves)

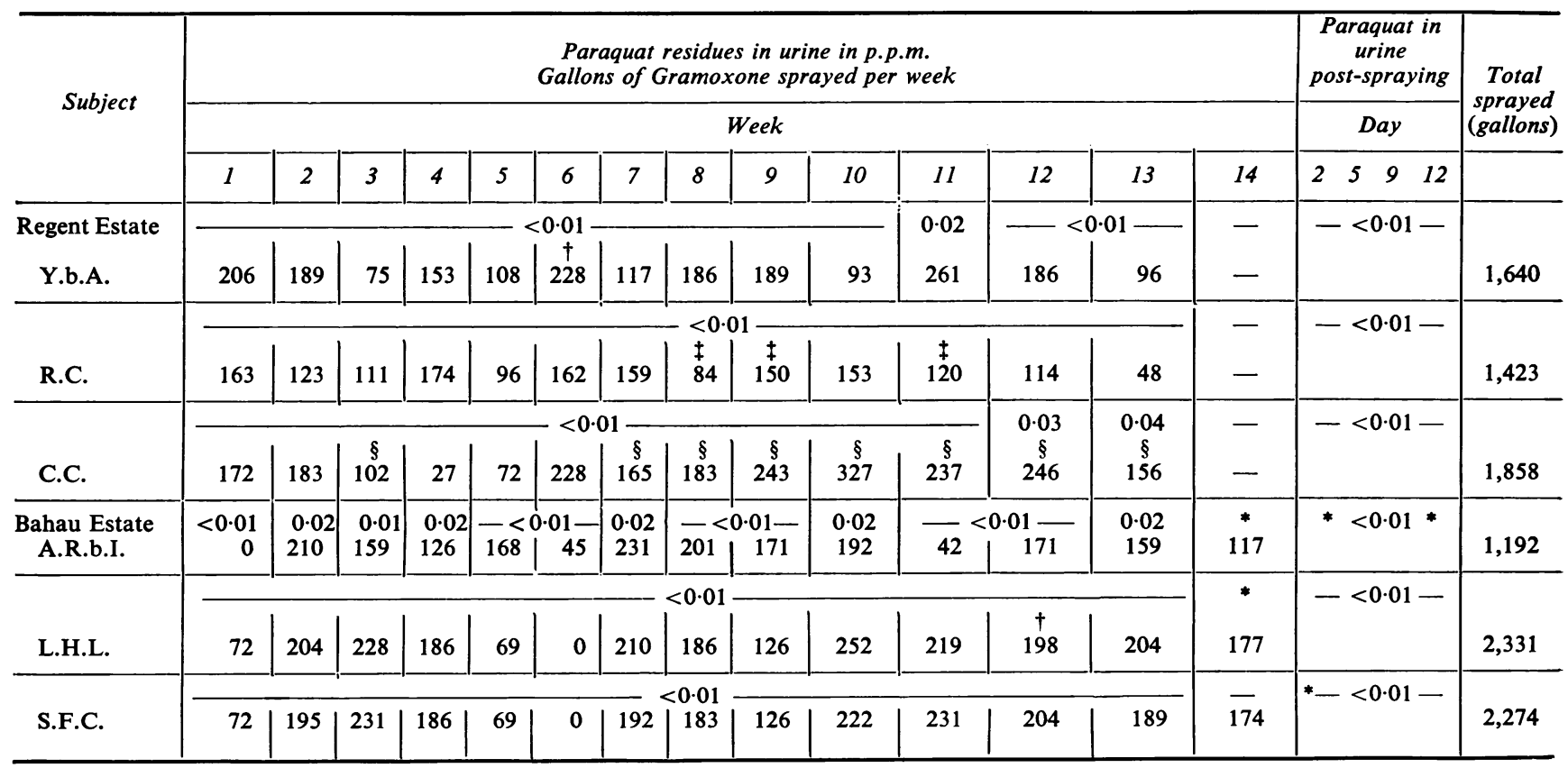

Regent

tScratch on hand.

$\ddagger$ Nail injury (8th week); abrasion on hand (9th week); skin irritation on both feet (11th week).

\$Finger injury (3rd week); abrasions on legs and hands, rash on feet from seepage of spray solution (7th week); injury to finger and toe (8th week); injury to toe (9th week); injury to leg (10th week); solution on both feet caused rash (12th week); dermatitis on ankle (13th week).

Bahau

*Insufficient sample.

†Laceration on finger (12th week). 
degree of contamination of the skin, and that gumboots were the most effective single protective measure in reducing this. Individual differences within the groups suggested that general care and attention to personal hygiene during and after operations is the most important factor, because it is by contamination of the skin that absorption occurs. As would be expected, the presence of minor skin abrasions on hands or legs was often associated with the finding of paraquat in the urine.

Some indication of the significance of the urinary paraquat concentrations found in these operators can be gained by comparing them with the urinary levels found in cases of accidental or suicidal ingestion in man. In two cases which survived, one (Leading article, Brit. med. J., 1967) where the amount taken was known (2.8 g.), a urine concentration of 44 p.p.m. was found in the first 24 hours, falling to 5 p.p.m. after 48 hours, to 1 p.p.m. at the end of a week, and to 0.36 and 0.05 p.p.m. at two and three weeks; in the other (Kerr, Patel, Scott, and Tompsett, 1968), where just over $2 \mathrm{~g}$. paraquat was thought to have been taken, a urinary concentration of 148 p.p.m. was found in a sample obtained some hours later and concentrations of 8 and 5 p.p.m. in the early stages of induced diuresis, falling below 1 p.p.m. in 24 hours. In contrast, from the information given by Matthew, Logan, Woodruff, and Heard (1968) in their fatal case in which a lung transplant was performed, it can be calculated that a concentration of approximately 400 p.p.m. occurred in a urine sample obtained 14

TABLE 5

Gramoxone Spraying Trial 1967

(FACE MASKS AND GUM BOOTS)

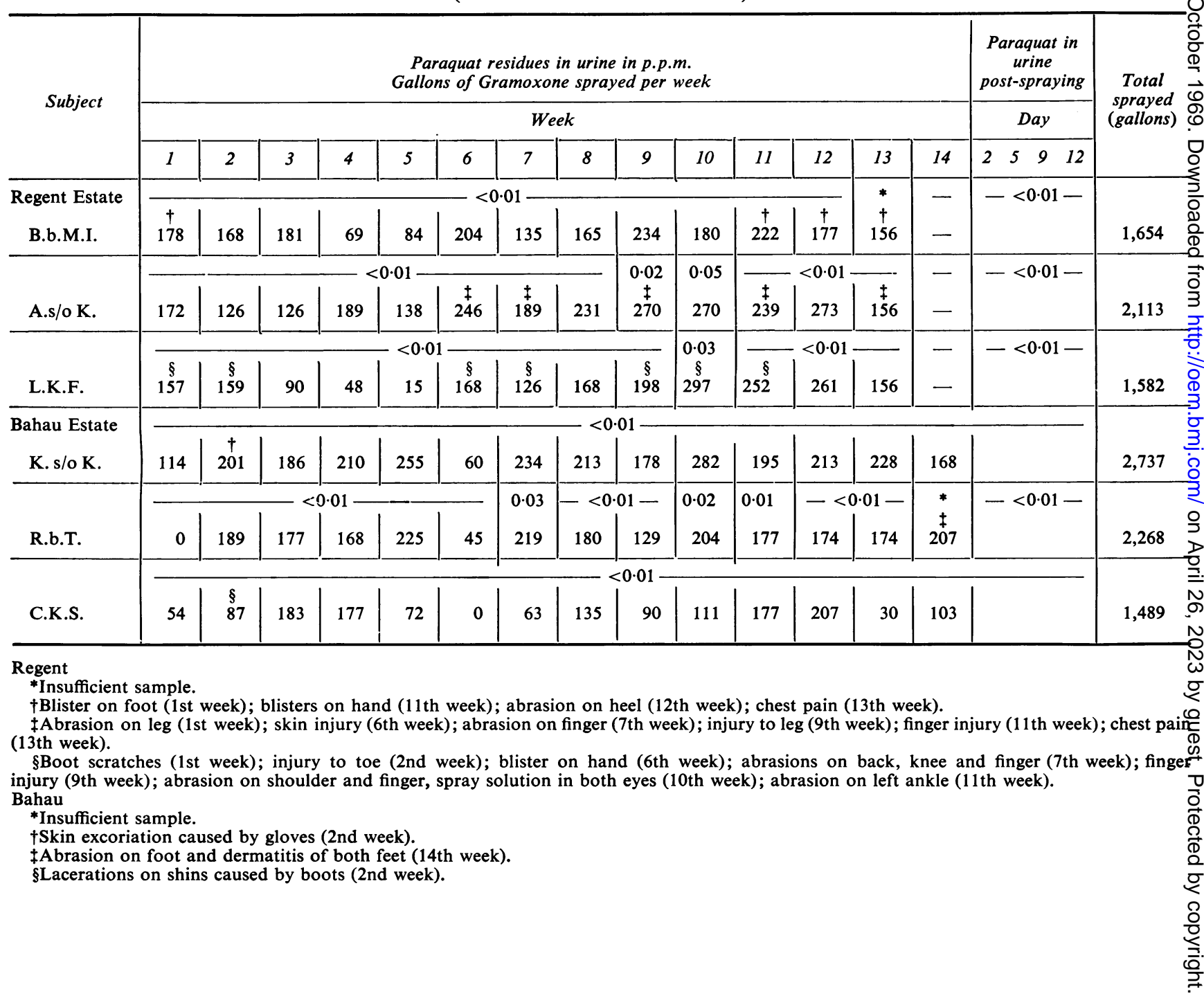


hours after ingestion; there was an average concentration of 22 p.p.m. during a subsequent 14-hour period of diuresis, and 3 p.p.m. and 0.6 to 0.7 p.p.m. at one and two weeks.

Apart from the present investigation, there is no information on the relation in man between sustained exposure to paraquat and the corresponding levels to be expected in the urine, but in dogs fed 50 p.p.m. paraquat dichloride daily for 27 months without effect on their growth or behaviour, an average urine concentration of 0.74 p.p.m. was found during the 26th month. In relation to these results and the observations from cases of poisoning in man, the levels of paraquat found intermittently in the 1965 (average 0.04 p.p.m.; peak 0.32 p.p.m.) and 1967 'rials (average 0.006; peak 0.15 p.p.m.) indicate that the operators were not subjected to any hazardous amount of systemic absorption.

In work to assess the hazards of inhalation, Gage (1968) found that aerosols of particles in the size range capable of being deposited on the alveolar surfaces of the lung (mass median diameter $<5 \mu$ ) have a high order of toxicity as a result of their strongly irritant action on the alveolar membranes. This is a direct effect, rapid in onset, and is not followed in surviving animals by the proliferative fibrotic lung changes of delayed onset that occur in fatal systemic poisoning by paraquat. Coarser aerosols $(80 \%$ of particles $>10 \mu)$ have a much lower toxicity since they do not reach the vulnerable alveolar surfaces. On the basis of this work a threshold limit value (T.L.V.) for respirable areosols (m.m.d. $<5 \mu$ ) of $0.1 \mathrm{mg} . / \mathrm{m}^{3}$ was suggested: continuous exposure to atmospheres containing this concentration will cause no ill-effects. On the assumption that all of the inhaled paraquat is retained, this limit would correspond to a urine concentration of 0.7 p.p.m. paraquat. In the event, a tentative T.L.V. of $0.5 \mathrm{mg} . / \mathrm{m}^{3}$ for total paraquat particulates has been adopted by the American Conference of Governmental Industrial Hygienists (1968) as a level which will prevent both nosebleeding and lung injury. Only high-pressure sprays or air-blast equipment are likely to produce aerosols with a significant proportion of small particles in the respirable size range, for large amounts of energy are required for this degree of sub-division of an aqueous solution. Gage and Seaborn (1968) have shown that some types of mistblower operated close to maximum output produce a significant proportion of respirable particles. Exposure to spray of lowpressure equipment such as the knapsack sprayers used in the present study may give rise to nosebleeding and other symptoms consequent on congestion of the nasal mucosa but will not carry the much more serious risk of lung injury, either from local action on the lung or from systemic absorption.

The assistance of the Chief Medical Officer, Dr. R. H. Isaac, and the co-operation of the management and staff of Dunlop Estates Berhad in the planning and clinical supervision of the trials are gratefully acknowledged. Dr. G. A. Watson, Mr. R. S. Elias, Dr. A. K. Seth, Mr. I. R. Kapon, and Inche Abu Bakar of Plant Protection Ltd. gave valuable help in the arrangements for the 1967 trial, and paraquat analyses were done by Dr. A. Calderbank's Section at Jealott's Hill Research Station, Plant Protection Limited. I am also indebted to Dr. B. Strickland, Radiologist to the Westminster Hospital, for reviewing all radiographs, and to Mrs. S. C. Cruickshank for preparing the tables.

\section{References}

American Conference of Governmental Industrial Hygienists, Threshold Limit Values of Air-borne Contaminants for 1968 , p. 11.

Bullivant, C. M. (1966). Accidental poisoning by paraquat: report of two cases in man. Brit. med. J., 1, 1272-3.

Calderbank, A., and Yuen, S. H. (1965). An ion-exchange method for determining paraquat residues in food crops. Analyst, 90, 99-106.

Cant, J. S., and Lewis, D. R. H. (1968). Ocular damage due to paraquat and diquat. Brit. med $J, 2,224$

Clark, D. G., McElligott, T. F., and Hurst, E. W. (1966). The toxicity of paraquat. Brit. J. industr. Med., 23, 126-132.

Conning, D. M. (1968). Personal communication.

Doyle, E. E., and Lee, G. A. McL. (1966). Quoted by Clark, D. G. and others, loc. cit.

Gage, J. C. (1968). Toxicity of paraquat and diquat aerosols generated by a size-selective cyclone: effect of particle size distribution. Brit. J. industr. Med., 25, 304-14.

- and Seaborn, D. J. (1968). Size distribution of fine droplets produced by a mistblower. J. agric. engng Res., 13 (2), 120-6.

Kerr, F., Patel, A. R., Scott, P. D. R., and Tompsett, S. L. (1968). Paraquat poisoning treated by forced diuresis. Brit. med. J., 3 , 290-1.

Leading article (1967). Poisoning from paraquat. Ibid., 3, 690-1.

Matthew, H., Logan, A., Woodruff, M. F. A., and Heard, B. (1968). Paraquat poisoning--lung transplantation. Ibid., 3, 759-63.

McElligott, T. F. (1967). Personal communication.

Sturman, D. (1966). Personal communication quoted by Swan, A. A. B. (1968). Ocular damage due to paraquat and diquat. Brit. med.J., 2, 624 .

Received for publication January 17, 1969. 